\title{
UMA ANÁLISE SOBRE OS PROGRAMAS DE FORMAÇÃO DE PROFESSORES PARA A EDUCAÇÃO BÁSICA
}

\author{
Marielda Ferreira Pryjma (UTFPR)* \\ https://orcid.org/0000-0003-1141-501X \\ Jamile Cristina Ajub Bridi (INSEP)** \\ https://orcid.org/0000-0003-4424-1351
}

\section{RESUMO}

As reflexões sobre a formação de professores são o tema deste estudo e tentam elucidar como um processo formativo está e esteve sendo realizado no interior de uma instituição pública de educação superior. A coleta de dados pautou-se em duas etapas para a sua realização: levantamento teórico sobre o tema formação de professores; levantamento e análise das propostas formativas indicadas nos documentos institucionais. Os resultados indicam que os Programas como o Esquema I e II, PLI, PARFOR, LIFE, PIBID alavancaram as ações institucionais voltadas para a formação de professores. As políticas se consolidaram nos bastidores institucionais e se transformaram em ações concretas; dessa forma, professores e pesquisadores debruçam-se sobre esses processos formativos, contribuindo, mesmo que modestamente, pela melhoria e aprimoramento dos cursos de licenciaturas na instituição. Finalmente considera-se que a formação de professores implica em uma permanente análise e reflexão, pois na medida em que se avança, novos desafios se apresentam, desencadeando novas necessidades e novas análises e reflexões; é o movimento dialético impulsionando os formadores de professores.

Palavras-chave: Formação de professores. Educação básica. Políticas educacionais.

\section{ABSTRACT}

\section{ANALYSIS ON THE PROGRAMS OF TEACHER TRAINING FOR BASIC EDUCATION}

The reflections on teacher training are the theme of this study and its try to

\footnotetext{
Doutora em Educação pela Universidade de São Paulo (USP). Professora Associada do Departamento de Educação da Universidade Tecnológica Federal do Paraná (UTFPR) e do Programa de Pós-Graduação em Educação da Universidade Federal do Paraná (PPGE/UFPR). Líder Coordenadora do Grupo de Pesquisa sobre Desenvolvimento Profissional Docente Transmutare (UFTPR). Participa da Rede Interinstitucional de Pesquisadores e Formação de Professores (RIPEFOR). E-mail: marielda@utfpr.edu.br

** Doutora em Educação pela Universidade Estadual de Campinas (Unicamp). Pedagoga na Universidade Tecnológica Federal do Paraná (UTFPR) e Professora do Magistério do Ensino Superior no Instituto Superior de Educação do Paranã (INSEP). Pesquisadora do Grupo de Pesquisa sobre Desenvolvimento Profissional Docente Transmutare (UFTPR). E-mail: jamilebridi@ utfpr.edu.br
} 
elucidate how a formative process is and it has been carried out within a public institution of higher education. Data collection was based in two stages for its realization: theoretical survey on the theme of teacher education; survey and analysis of the formative proposals indicated in the institutional documents. The results indicate that formative process, such as Scheme I and II, PLI, PARFOR, LIFE, PIBID leveraged institutional actions aimed at teacher training. The policies have been consolidating behind the institutional scenes and have been becoming concrete actions. So, teachers and researchers pursue these formative processes, contributing, even modestly, the improvement teaching major. Finally, teacher training implies a permanent analysis and reflection, because according to the evolution, new challenges are triggering new needs, new analyses and reflections. It is the dialectical movement driving teacher trainers.

Keywords: Teacher training. Basic education. Educational policies.

\section{RESUMEN}

\section{ANÁLISIS DE PROGRAMAS DE FORMACIÓN DE PROFESORES PARA LA EDUCACIÓN BÁSICA}

Las reflexiones sobre la formación del profesorado son el tema de este estudio y tratan de esclarecer cómo es y se ha llevado a cabo un proceso formativo dentro de una institución pública de educación superior. La busca de datos se basó en dos etapas para su realización: revisión teórica sobre el tema de la formación del profesorado; estudio y análisis de las propuestas formativas indicadas en los documentos institucionales. Los resultados indican que programas como Esquemas I y II, PLI, PARFOR, LIFE, PIBID aprovecharon las acciones institucionales dirigidas a la formación del profesorado. Las políticas se han consolidado tras las escenas institucionales y se han convertido en acciones concretas y profesores, los investigadores se centran en estos procesos formativos, contribuyendo, aunque modestamente, a la mejora y progreso de grados en la institución. Por último, se considera que la formación del profesorado implica un análisis y una reflexión permanentes, ya que a medida que el progreso, los nuevos retos están desencadenando nuevas necesidades y nuevos análisis y reflexiones, es el movimiento dialéctico que impulsa formadores de maestros. Palabras clave: Formación del profesorado. Educación básica. Políticas educativas.

\section{Introdução}

No panorama nacional, as políticas que visam à formação de professores permanecem em discussão, impulsionando o número de pesquisas sobre esse tema na área de educação. Análise sobre os processos formativos dos professores têm sido sistemáticos nos últimos anos no país, notadamente aqueles que enfocam a educação básica brasileira. 0 contexto nacional tem sofrido modificações no que se refere às políticas destinadas a essa formação, e o grupo de pesquisa responsável por este estudo encontrou nessas transformações a justificativa para esta investigação. A primeira razão se pauta na promulgação da Lei de Diretrizes e Bases da Educação Nacional (BRASIL, 1996), que 
renovou e direcionou claramente as análises sobre a formação docente no país, ampliando e concretizando inúmeras investigações da década de 1990 para cá, permitindo que um cenário fosse constituído sobre a temática. Outro fator determinante para desencadear essa análise foi a proposição do Programa de Apoio a Planos de Reestruturação e Expansão das Universidades Federais (REUNI), pois afetou diretamente o contexto da instituição de educação superior a que o grupo de pesquisa está vinculado. Esclarece-se que o REUNI foi instituído pelo Decreto no 6.096, de 24 de abril de 2007 (BRASIL, 2007), e constitui-se em uma das ações que previa o aumento de vagas nos cursos de graduação, a inovação pedagógica por meio de metodologias diferenciadas e o combate à evasão.

Foi a partir dessas reflexões que a proposta deste estudo se pautou e os questionamentos feitos levaram a equipe de pesquisadores a tentar compreender como esse processo formativo está e esteve sendo realizado no interior de uma instituição pública de educação superior no Brasil. Ao analisar uma realidade local seria possível entender uma realidade global, visto que as interações que ocorrem no meio acadêmico revelam que os processos formativos, para se efetivarem, se desenvolvem com o apoio dos pares, em grupos, em redes, demonstrando que a sociedade necessita do trabalho coletivo e das análises sistêmicas. Desta forma, a formação de professores é o tema central deste estudo e encontra em um contexto institucional a sua análise e reflexão. Assim, este parecer analisa as propostas formativas voltadas para o professor da educação básica desenvolvida por uma instituição de educação superior, para apresentar e analisar o contexto sócio-histórico dessa formação.

Nesse contexto, a pesquisa documental delineou o encaminhamento metodológico, priorizando a abordagem qualitativa por considerar que a fonte de dados encontra no próprio ambiente da pesquisa sua sustentação, permitindo que o entendimento dos resultados refletisse os pressupostos teóricos e constituísse um novo conhecimento a partir dessa reflexão.

Como procedimentos de coleta de dados, esse estudo pautou-se em duas etapas essenciais para a sua realização, a saber: a) levantamento teórico sobre o tema formação de professores; b) levantamento e análise das propostas formativas indicadas nos documentos institucionais. A primeira etapa consistiu na pesquisa teórica acerca do tema em estudo, com o intuito de ampliar e apropriar-se de fundamentos que permitiriam uma análise consistente dos dados de pesquisa. A segunda considerou exclusivamente os documentos institucionais que apresentaram as propostas voltadas ao processo de formação do professor da educação básica e que foram reveladas nas políticas institucionais. Ambas as etapas, em vários momentos de pesquisa, ocorreram concomitantemente.

A opção pelo uso de documentos se deu porque eles oferecem uma enorme gama de dados que permitem recuperar, revisar e revisitar informações que ampliam o entendimento sobre o objeto de compreensão. Outro fator que levou à escolha da pesquisa documental como estratégia metodológica para a coleta de dados foi o uso de documentos consente adicionar a dimensão do tempo à compreensão do social (SÁ-SILVA; ALMEIDA; GUINDANI, 2009). A análise documental favorece a observação do processo de maturação ou de evolução de indivíduos, grupos, conceitos, conhecimentos, comportamentos, mentalidades, práticas, entre outros. Ressalta-se que o termo "análise documental" foi uma opção metodológica que está sustentada na explicação de que esse procedimento possibilita a identificação de dados nos documentos a partir do objeto de estudo (SÁ-SILVA; ALMEIDA; GUINDANI, 2009).

Os documentos utilizados para a realização deste estudo envolveram aqueles que estavam vinculados ao departamento responsável pela formação na instituição desde a primeira 
proposta existente na universidade em 1984, incluindo a documentação da legislação brasileira e institucional, notadamente nos relatórios, editais e demais dados que expressem as intenções formativas das propostas voltadas para a formação de professores.

Assim, após todos os documentos serem selecionados, foram explorados considerando o aporte teórico da análise de conteúdo (BARDIN, 2009), utilizando, particularmente, os seguintes pressupostos: a) "a análise de conteúdo aparece como um conjunto de técnicas de análise das comunicações que utiliza procedimentos sistemáticos e objetivos de descrição do conteúdo das mensagens" (BARDIN, 2009, p. 40); b) compreender o sentido da comunicação para explicar e sistematizar o conteúdo das mensagens, particularmente para conhecer o que está por trás das palavras, em busca de outras realidades apresentadas nelas; c) por fim, "a finalidade é sempre a mesma, a saber, esclarecer a especificidade e o campo de ação da análise de conteúdo" (BARDIN, 2009, p. 47). Os documentos, dessa forma, foram analisados para esclarecer e explicar a partir de um contexto e ampliar a compreensão do texto original (BARDIN, 2009).

A instituição em questão, historicamente, dedicou-se à formação profissional, focalizando sua atenção nos cursos técnicos de Ensino Médio durante quase um século. No entanto, ela foi responsável pela formação pedagógica de inúmeros profissionais da área de educação. Os primeiros cursos, como já citado, tiveram a sua oferta iniciada em 1984 e foram criados em caráter emergencial e extraordinário, já que buscava formação para a docência dos profissionais que poderiam atuar como professores na educação profissional. Estrategicamente, a apresentação das políticas nacionais de formação de professores para a educação profissional será o pano de fundo deste estudo para que se possa situar os diferentes momentos históricos do país e da Instituição de Ensino Superior (IES). Este estudo permitiu revelar a trajetória formati- va da instituição e se constitui uma valiosa contribuição ao contexto sócio-histórico da formação de professores no país.

\section{A formação de professores para a educação profissional}

A formação de professores que atuariam nas Escolas Técnicas Industriais ocorreria, a partir da Lei de Diretrizes e Bases da Educação de 1961, por meio dos cursos específicos de educação técnica e as disciplinas de educação geral teriam os seus professores formados, em nível superior, nas faculdades de filosofia, ciências e letras (MAZZOTA, 1985). Esta distinção, em relação à formação, para atuação como professor foi superada pela Lei $\mathrm{n}$ - 5.540, promulgada em 1968 (BRASIL, 1968), quando ficou estabelecido que os professores que atuariam nos cursos de segundo grau, tanto nas disciplinas técnicas como nas gerais, deveriam ocorrer em nível superior. Todavia, esta exigência legal apresentou uma alternativa, na medida em que o Decreto-Lei no 464, de 1969 (BRASIL, 1969) possibilitou os exames de suficiência para habilitar professores nas áreas que houvesse falta de profissionais certificados.

As Diretorias de Ensino Comercial, Agrícola e Industrial propuseram ações diferenciadas para a formação de professores para o ensino profissional, e destas pode-se destacar a Diretoria de Ensino Industrial, que apresentou, em 1969, um plano de formação de professores mais elaborado. 0 plano previa a formação de professores por meio de dois esquemas distintos: a) Esquema I, destinado aos profissionais de nível superior, que oferecia uma formação pedagógica com duração de 720 horas/aula; e b) Esquema II, destinado aos técnicos de nível médio que oferecia, concomitantemente, a formação específica e a formação pedagógica, totalizando uma carga horária de 1600 horas / aula. A unificação das três diretorias de ensino, em 1971, deu origem ao Departamento de Ensino Médio (DEM) e esta foi determinante 
para a história do ensino técnico, visto que representou o início de uma política distinta para a formação do professor deste nível de ensino com a promulgação da Portaria no 432, de 1971 (BRASIL, 1971a), que criou os cursos de formação de professores nos mesmos moldes apresentados pela antiga Diretoria de Ensino Industrial.

Com a obrigatoriedade da profissionalização, estabelecida pela Lei no 5.692, de 1971 (BRASIL, 1971b), a política de formação de professores defrontou-se com uma demanda efetiva: agora todo o ensino de segundo grau deveria ser ministrado por professores habilitados para lecionarem as disciplinas profissionalizantes. Isto gerou um problema político, já que a demanda de professores habilitados não poderia ser atendida em curto e médio prazo. Esta situação comprometeu a qualidade da formação docente e os cursos Esquema I e Esquema II passaram a ser ofertados em instituições sem tradição na área técnica e/ou educacional, comprometendo diretamente as propostas de formação de professores. A necessidade de atender aos quesitos legais de certificação fez com que muitos dos cursos oferecidos assumissem um caráter emergencial, com regimes especiais e somente a apresentação superficial de conteúdos considerados necessários ao bom desempenho da atividade docente.

Neste mesmo contexto, as universidades não tinham a tradição de formar docentes para o ensino técnico e a Lei no 5.540 (BRASIL, 1968) volta-se para a abertura e reconhecimento de cursos em nível superior, não assumindo essa responsabilidade. Após inúmeras discussões e problemas advindos dessas políticas, o Conselho Nacional de Educação, por meio do Parecer CNE no 335 (BRASIL, 1982a), determinou que tanto a licenciatura quanto os cursos Esquema I e II seriam considerados alternativas válidas para a formação de professores para o ensino técnico. Contudo, também regulamentou que estes cursos teriam que seguir as mesmas regulamentações e procedimentos exigidos para outros cursos de graduação (Quadro 1).

A obrigatoriedade pelo ensino profissionalizante deixa de existir em 1982, a partir da promulgação da Lei no 7.044, de 1982 (BRASIL, 1982b), e a necessidade da formação de professores para o ensino técnico permanece clara. Em 1986, os Centros Federais de Educação Tecnológica dos Estados do Paraná, Minas Gerais e Rio de Janeiro assumem a responsabilidade de oferecer cursos de formação de professores para este nível de ensino. Somente em 1997 os cursos de formação de professores, nos moldes apresentados anteriormente, foram extintos, sendo substituídos por um Programa Especial de Formação Pedagógica, destinado aos profissionais portadores de curso superior, que habilitaria pedagogicamente a estes atuarem no magistério (BRASIL, 1997).

Esse Programa Especial teve o Centro Federal de Educação Tecnológica (CEFET/PR) designado, por meio do Decreto no 3.462, de 2000 (BRASIL, 2000b), como instituição formadora de professores para as áreas científicas e tecnológicas, o qual fez a opção pela formação pedagógica dos professores que ministrariam as disciplinas do ensino básico e médio. Como essa mesma instituição iniciou a formação de professores para o ensino técnico em 1984, a sua vasta experiência possibilitou que fossem ofertadas turmas desse Programa Especial no Estado do Paraná e em outros Estados da Federação. A proposta do Programa Especial de Formação Pedagógica (BRASIL, 2000a) colocou em discussão o processo de formação e aprendizagem dos professores, destacando que a formação inicial como a preparação profissional tem papel crucial para possibilitar aos professores apropriação de determinados conhecimentos e experimentar, em seu próprio processo de aprendizagem, o desenvolvimento de competências necessárias para atuar nesse novo cenário. 
Quadro 1 - Comparativo entre o Curso Esquema I e o Programa Especial de Formação Pedagógica

\begin{tabular}{|l|l|}
\hline Curso Esquema I & Programa Especial de Formação Pedagógica \\
\hline $\begin{array}{l}\text { Candidatos: portadores de diploma de curso } \\
\text { superior, relacionado com a habilitação } \\
\text { pretendida, excetuando-se os cursos de } \\
\text { licenciaturas. }\end{array}$ & $\begin{array}{l}\text { Candidatos: portadores de diploma de curso } \\
\text { superior, relacionado com a habilitação } \\
\text { pretendida. }\end{array}$ \\
\hline $\begin{array}{l}\text { Disciplinas para habilitação: até } 3 \text { disciplinas } \\
\text { dentro da área de formação específica, que } \\
\text { tenha sido estudada no mínimo } 160 \text { horas na } \\
\text { graduação. }\end{array}$ & $\begin{array}{l}\text { Disciplinas para habilitação: uma disciplina que } \\
\text { tenha sido estudada no mínimo } 160 \text { horas na } \\
\text { graduação. }\end{array}$ \\
\hline Carga horária: 900 horas/aula. & Carga horária: 600 horas/aula \\
\hline $\begin{array}{l}\text { Prática de ensino: prevista no final do curso, com } \\
\text { duração de } 315 \text { horas/aula. }\end{array}$ & $\begin{array}{l}\text { Prática de ensino: prevista para acontecer } \\
\text { durante toda a execução do programa, com } \\
\text { duração de 300 horas/aula. }\end{array}$ \\
\hline Diploma de licenciatura plena ao final do curso. & $\begin{array}{l}\text { Certificado de licenciatura plena ao final do } \\
\text { programa. }\end{array}$ \\
\hline
\end{tabular}

Fonte: Elaborado pelas autoras deste artigo com base em Brasil (1982a, 1997).

0 documento que regularizou o programa de formação pedagógica tornou evidente que seria imprescindível, face às novas demandas sociais, rever os modelos de formação docente, buscando: a) fomentar e fortalecer processos de mudança no interior das instituições formadoras; b) fortalecer e aprimorar a capacidade acadêmica e profissional dos docentes formadores; c) atualizar e aperfeiçoar os currículos, face às novas exigências; d) articular a formação com as demandas da realidade escolar na sociedade contemporânea; e) articular a formação com as mudanças em curso na organização pedagógica e curricular da educação básica brasileira, preparando para serem agentes dessas mudanças; f) melhorar a oferta de recursos bibliográficos e tecnológicos em todas as instituições ou programas de formação (BRASIL, 2000a).

Todavia, a qualificação profissional dos professores dependerá, fundamentalmente, de algumas mudanças que envolveriam: a) o estabelecimento de um sistema nacional de desenvolvimento profissional contínuo para todos os professores do sistema educacional; b) o fortalecimento dos vínculos entre as instituições formadoras e o sistema educacional, suas escolas e seus professores; c) a formulação, discussão e implementação de um sistema de avaliação e certificação de cursos, diplomas e competências de professores em âmbito nacional (BRASIL, 2000a). Os princípios da Lei de Diretrizes e Bases da Educação Nacional (LDB) embasaram-se nestes princípios para a formação de professores e esta, de fato, foi direcionada para a profissionalização do professor e do atendimento das necessidades da Educação Básica na sociedade brasileira.

Assim, a LDB (BRASIL, 1996) trouxe como desafio uma nova maneira de formar e atualizar os professores, estimulando a educação continuada (aquela que se realiza durante o transcorrer de toda a vida profissional em decorrência de necessidades de atualização), instigando os estabelecimentos formadores a se inovarem institucional e estruturalmente. As propostas curriculares para a formação de professores do Esquema I e II foram alteradas e reconstruídas considerando uma nova abordagem teórica metodológica. Partindo de grandes temas para discussão e aprofundamento por meio de estudos, o novo currículo enfocou amplamente as dimensões do ensino, a escola como instituição e organização, os paradigmas da ciência, a redefinição do papel do professor, as competências para ensinar e participar da gestão do ensino. 
Todos esses aspectos consideraram as novas posturas e comportamentos diante dos desafios sociais, as tendências para o ensino, as concepções e os princípios psicopedagógicos que devem nortear as decisões sobre a aprendizagem e as concepções sobre tecnologia e educação tecnológica. Todos os temas foram organizados em torno de núcleos assim designados: Núcleo Contextual, Núcleo Estrutural e Núcleo Integrador. Tais núcleos tiveram o objetivo de construir novos conhecimentos e habilidades necessários para a formação do docente, possibilitando o desenvolvimento profissional articulado com a teoria e a prática, ultrapassando os modelos tradicionais de formação, em que as disciplinas fragmentavam os conhecimentos em compartimentos estanques. A proposta considerou, também, que para o docente compreender e transformar a realidade do contexto em que está inserido, todos os temas indicados seriam trabalhados com a participação dele em pesquisas em educação, seminários e estágios.

O Núcleo Contextual foi constituído pelos seguintes temas: gestão escolar, a instituição escolar como organização e profissão professor. $\mathrm{O}$ objetivos destes temas foram: propiciar a compreensão de todos os mecanismos que envolvem a organização e estruturação de uma instituição de ensino nos seus diferentes níveis; desenvolver o processo gerencial das relações humanas e profissionais que se desenvolvem nas instituições; avaliar o papel da instituição de ensino como agência de transformação da realidade na qual está inserida.

O Núcleo Estrutural, por sua vez, desenvolveu temas como paradigmas da educação, dimensão da ciência e da tecnologia no ambiente educacional e concepções psicopedagógicas do processo de ensino e aprendizagem, atendendo dessa maneira o que preconiza a mencionada Resolução, cuja principal finalidade é oportunizar ao professor a aquisição de competências e o desenvolvimento de habilidades necessárias ao exercício das atividades inerentes à sala de aula, à compreensão do seu papel de agente de transformação e à sua prática pedagógica e responsabilidade no desenvolvimento de pesquisas educacionais.

O Núcleo Integrador foi desenvolvido por meio do planejamento multidisciplinar, objetivando uma visão global da realidade na qual está inserida a prática do educador, tendo a interdisciplinaridade como elo articulador das diferentes áreas do conhecimento. Cada tema proposto ficou sob a responsabilidade de um professor que tinha como incumbência organizar, planejar e desenvolver os conteúdos estabelecidos, podendo-se valer de diferentes metodologias de ensino, possibilitando ampla visão da interação entre teoria e prática sob diferentes enfoques.

A disciplina de Metodologia da Pesquisa em Educação acompanhou todo o processo de formação, possibilitando a familiaridade com os procedimentos de investigação sobre os objetos de ensino e com o processo histórico de produção do conhecimento, auxiliando o professor a fazer uso da contribuição dada pela pesquisa. A intenção dessa abordagem foi dar ao conhecimento um novo significado, deixando de ter uma função informativa para ser uma experiência de formação e reconstrução, auxiliando efetivamente o educador na apreensão e transformação da própria prática. Assim, o processo de avaliação deveria ser planejado de forma que o educador pudesse ser avaliado sob diferentes perspectivas, ou seja, como elemento responsável pela gestão escolar, como facilitador do processo de ensino e aprendizagem e como pesquisador da sua própria prática pedagógica, além da sua atuação em sala de aula.

A formação inicial como preparação profissional tem papel crucial para possibilitar que os professores se apropriem de determinados conhecimentos e possam experimentar, em seu próprio processo de aprendizagem, o desenvolvimento de competências para atuar no novo cenário. A formação destes profissionais foi bastante desafiadora, visto que se tratava de especialistas em diferentes áreas do conheci- 
mento e buscavam uma qualificação profissional para atuarem como professores.

As mudanças nas bases legais e curriculares traziam novas abordagens a serem desenvolvidas e as instituições formadoras deveriam assegurar que tais processos ocorreriam nesses cursos. A solução encontrada para atender a este desafio ocorreu de forma coletiva e a equipe de professores, que iria atuar nestes cursos, encontrou respostas criativas para o currículo, organizando uma proposta a ser desenvolvida sob esta nova tendência. Em 2011 a proposta curricular sofreu uma nova alteração e o programa especial de formação teve sua configuração bastante alterada. A carga horária foi ampliada em 200 horas e as atividades teórico-práticas passaram a ser pano de fundo da nova proposta. 0 eixo articulador do novo currículo passou a ser a prática docente e esta atendeu as necessidades detectadas e demandas trazidas a partir dos resultados das avaliações feitas em relação ao próprio curso.

\section{Os cursos de licenciaturas na IES}

No contexto nacional, segundo números do último censo da educação superior apresentado pelo Instituto Nacional de Estudos e Pesquisas Educacionais Anísio Teixeira, sinopse de 2017, são ofertados 26 tipos de cursos de licenciatura no Brasil, totalizando 7.272 cursos de licenciatura ofertados por instituições de educação superior credenciados pelo Ministério da Educação (INSTITUTO NACIONAL DE ESTUDOS E PESQUISAS EDUCACIONAIS ANÍSIO TEIXEIRA, 2018) (ver Quadro 2).

Quadro 2 - Número de cursos de licenciatura no país, 2017

\begin{tabular}{|l|c|c|c|c|}
\hline \multicolumn{1}{|c|}{ Cursos } & Bacharelado & Licenciatura & Tecnólogo & Total \\
\hline Número de Cursos & 21.103 & 7.272 & 7.005 & 35.380 \\
\hline Pública & 5.436 & 3.792 & 1.197 & 10.425 \\
\hline Federal & 3.607 & 2.083 & 663 & 6.353 \\
\hline Estadual & 1.476 & 1.525 & 486 & 3.487 \\
\hline Municipal & 353 & 184 & 48 & 585 \\
\hline Privada & 15.667 & 3.480 & 5.808 & 24.955 \\
\hline
\end{tabular}

Fonte: Instituto Nacional de Estudos e Pesquisas Educacionais Anísio Teixeira (2018).

Apesar desse indicador apresentar uma pequena diferença, a oferta de cursos ofertados no sistema público de ensino é maior; essa ampliação ocorreu tanto no número de instituições responsáveis pela oferta dos cursos, quanto no número de cursos disponibilizados.

Atualmente os cursos de formação para professores têm nas instituições públicas de ensino a sua maior oferta, demonstrando uma redução entre as instituições de iniciativa privada. ${ }^{1}$ Esse fato pode ter ocorrido em razão

1 O relatório de 2010 indica que havia um número maior de instituições de educação superior privadas que ofertavam cursos de licenciatura na ocasião (INSTITUTO NACIONAL DE ESTUDOS E PESQUISAS EDUCACIONAIS ANÍSIO TEIXEIRA, 2010). do programa REUNI, que possibilitou, além da ampliação do número de instituições federais no país, a inclusão das licenciaturas nas suas políticas formativas, aumentando significativamente a oferta de licenciaturas nos últimos anos no país.

A promulgação da Lei de Diretrizes e Bases da Educação Nacional, Lei 9.394, de 1996 (BRASIL, 1996), conduziu a discussão e debates sistemáticos sobre a formação docente no país, fortalecendo estudos e pesquisas na área a partir da década de 1990. 0 número de cursos de licenciatura aumentou pelo estímulo dado pelo Programa de Apoio a Planos de Reestruturação e Expansão das Universidades 
Federais (REUNI) (BRASIL, 2007). O REUNI foi instituído pelo Decreto no 6.096 , de 24 de abril de 2007 (BRASIL, 2007), e constitui-se em uma das ações que previa o aumento de vagas nos cursos de graduação, a inovação pedagógica por meio de metodologias diferenciadas e o combate à evasão.

O INEP apresenta um panorama geral das graduações no país e em seus relatórios indicam os resultados subdivididos por "Áreas Gerais, Áreas Detalhadas e Programas e/ou Cursos" (INSTITUTO NACIONAL DE ESTUDOS E PESQUISAS EDUCACIONAIS ANÍSIO TEIXEIRA, 2017); e no caso da formação para a docência, designa três diferentes nomenclaturas ${ }^{2}$ para

2 São nomenclaturas utilizadas na sinopse da educação superior as seguintes terminologias para a formação de professor da educação básica: Formação de professor das séries finais do ensino fundamental; Formação de professor das séries iniciais do ensino fundamental; Formação de professor de educação especial; Formação de professor de educação física para educação básica; Formação de professor do ensino fundamental; Formação de professor do ensino médio; Formação de professor para a educação básica; Licenciatura Intercultural; Licenciatura Intercultural Indígena. São nomenclaturas utilizadas na sinopse da educação superior as seguintes terminologias para a formação de professor das disciplinas profissionais: Formação de professor de artes (educação artística); Formação de professor de artes plásticas; Formação de professor de artes visuais; Formação de professor de biblioteconomia; Formação de professor de computação (informática); Formação de professor de dança; Formação de professor de disciplinas do setor primário (agricultura, pecuária, etc.); Formação de professor de economia doméstica; Formação de professor de educação física; Formação de professor de enfermagem; Formação de professor de mecânica; Formação de professor de música; Formação de professor de teatro (artes cênicas); Formação de professor do ensino técnico; Formação de professor em segurança pública; Licenciatura para a educação profissional e tecnológica. São nomenclaturas utilizadas na sinopse da educação superior as seguintes terminologias para a formação de professor das áreas específicas: Formação de professor de biologia; Formação de professor de ciências; Formação de professor de educação religiosa; Formação de professor de estudos sociais; Formação de professor de filosofia; Formação de professor de física; Formação de professor de geografia; Formação de professor de história; Formação de professor de letras; Formação de professor de linguística; Formação de professor de língua/literatura estrangeira moderna; Formação de professor de língua/literatura vernácula (português); Formação de professor de língua/literatura vernácula e língua estrangeira moderna; Formação de professor de matemática; Formação de professor de psicologia; Formação de professor de química; Formação de professor de sociologia; Formação de professor em ciências sociais (INSTITUTO NACIONAL DE ESTUDOS E distinguir os tipos de proposta: formação de professor da educação básica, formação de professor de disciplinas profissionais e formação de professor das áreas específicas (INSTITUTO NACIONAL DE ESTUDOS E PESQUISAS EDUCACIONAIS ANÍSIO TEIXEIRA, 2017). Entende-se por "formação de professor da educação básica" os cursos de formação voltados para esse fim, sem mencionar uma área do conhecimento ou alguma particularidade formativa. Já os cursos destinados à formação profissional buscam assegurar a formação do professor que atuará na educação básica integrada à educação profissional. Já os cursos voltados para a formação de professores das áreas específicas representam as áreas tradicionalmente denominadas específicas, como português, matemática, física, química, biologia, entre outras.

Atualmente, os dados do relatório divulgado em 2019 (UNIVERSIDADE TECNOLÓGICA FEDERAL DO PARANÁ, 2019) indicam que existem 3.182 estudantes matriculados nos cursos de licenciatura na IES em todo o Estado.

Outro fator determinante para assegurar a qualidade da formação está relacionado ao Núcleo Docente Estruturante (NDE), que é composto por um grupo de docentes vinculados às licenciaturas com atribuições acadêmicas voltadas ao processo de concepção do curso, acompanhamento, atualização e consolidação de cada projeto pedagógico (BRASIL, 2010a).

Os professores que compõem esses núcleos acompanham o desenvolvimento da proposta dos cursos e permanentemente analisam se a identidade, o propósito e as intenções formativas contidas nos cursos de graduação estão adequados aos princípios institucionais de formação acadêmica, bem como as bases legais do país. Particularmente a partir de 2015, uma das principais incumbências do NDE esteve direcionada ao ajustamento dos projetos pedagógicos dos cursos de licenciatura, pois com a promulgação da Resolução no 2, em 2015, (BRASIL, 2015) novas regulamentações para a formação docente foram implantadas.

PESQUISAS EDUCACIONAIS ANÍSIO TEIXEIRA, 2017). 
Quadro 3 - Cursos de Licenciaturas por Campus, ano de criação, número de alunos e conceito

\begin{tabular}{|c|l|c|c|c|c|}
\hline Campus & \multicolumn{1}{|c|}{ Curso (em atividade) } & $\begin{array}{c}\text { Ano de } \\
\text { criação }\end{array}$ & $\begin{array}{c}\text { No alunos } \\
\text { ativos }\end{array}$ & $\begin{array}{c}\text {N}^{\circ} \text { Alunos } \\
\text { Formados }\end{array}$ & $\begin{array}{c}\text { Conceito } \\
2017\end{array}$ \\
\hline AP & Licenciatura em Química & 2011 & 161 & 39 & 4 \\
\hline CM & Licenciatura em Química & 2011 & 183 & 53 & 4 \\
\hline CP & Licenciatura em Matemática & 2011 & 200 & 60 & 4 \\
\hline CT & Licenciatura em Física & 2009 & 259 & 39 & 4 \\
\hline CT & Licenciatura em Letras Inglês & 2016 & 200 & 0 & --- \\
\hline CT & Licenciatura em Letras Português & 2016 & 204 & 0 & -- \\
\hline CT & Licenciatura em Matemática & 2011 & 227 & 37 & 4 \\
\hline CT & Licenciatura em Química & 2012 & 130 & 31 & 4 \\
\hline DV & Licenciatura em Ciências Biológicas & 2011 & 249 & 77 & 4 \\
\hline FB & Licenciatura em Informática & 2011 & 201 & 34 & 4 \\
\hline LD & Licenciatura em Química & 2011 & 184 & 37 & 4 \\
\hline MD & Licenciatura em Química & 2013 & 164 & 15 & 4 \\
\hline PB & Licenciatura em Letras Português-Inglês & 2007 & 281 & 246 & 4 \\
\hline PB & Licenciatura em Matemática & 2018 & 50 & 0 & 4 \\
\hline PG & Curso de Licenciatura em Ciências Biológicas & 2017 & 117 & 0 & --- \\
\hline SH & Licenciatura em Ciências Biológicas & 2014 & 180 & 10 & 5 \\
\hline TD & Licenciatura em Matemática & 2011 & 156 & 45 & 4 \\
\hline
\end{tabular}

Fonte: Elaborado pelas autoras deste artigo.

\section{A IES no contexto das políticas nacionais}

Antes de iniciar a análise dos desdobramentos das políticas nacionais na IES investigada, cabe uma breve contextualização dessas instituições no país. Entre os anos de 1993 e 1994, o MEC conduziu a elaboração do Plano Decenal de Educação para Todos, em processos ascendentes, gerando planos municipais, estaduais e, por fim, o nacional. Os dirigentes da educação daquele momento, em sua maioria, seja no âmbito municipal ou estadual, seja em órgãos públicos ou como componentes de organizações da sociedade civil, contribuíram e tiveram alguma forma de participação nesse processo.

A LDB retomou o mandato de Jomtien, instituindo a Década da Educação, a vigorar a partir de de- zembro de 1997 (art. 87) e determinando à União encaminhar ao Poder Legislativo, no prazo de um ano, o Plano Nacional de Educação. Novamente se obtêm avanços: o plano deve ter sintonia com a Declaração Mundial de Educação para Todos e a duração de uma década. 0 ano de 1997 foi dedicado à sua formulação. Seguiram-se três anos: 1998, 1999 e 2000 de tramitação legislativa no Congresso Nacional. Ali, um amplo e intenso programa de debates foi instaurado, emendas foram apresentadas, sugestões, encaminhadas. Até que em 9 de janeiro de 2001, o Presidente sancionou a lei que institui o PNE. O PNE, portanto, consolida um desejo e um esforço histórico de mais de 60 anos. (BRASIL, 2001, p. 14).

Ao sancionar o texto, ora aprovado pelo Congresso, o presidente da República Fernando Henrique Cardoso fez nove vetos aos subitens do Plano que promoviam alterações ou recomendavam a ampliação de recursos financeiros 
para a educação, dos quais cinco se referiam diretamente à "educação superior". Naquele momento, o foco era a formação do docente para a educação básica.

Em abril de 2007, o MEC lançou o Plano de Desenvolvimento da Educação (PDE), o qual se constitui basicamente em um conjunto de mais de 40 ações e programas voltados para a educação básica, superior, profissional e continuada, e, simultaneamente, aprovou o Decreto no 6.094 (BRASIL, 2007b), que dispõe sobre o Plano de Metas Compromisso Todos pela Educação, considerado alicerce jurídico do PDE.

Em 2007, com a criação do Plano de Desenvolvimento da Educação (PDE) (BRASIL, 2007c), muitas ações foram planejadas e efetivadas de modo a contemplar a educação básica, a educação profissional e a educação superior, com articulação entre estes níveis.

O Decreto n.o 6.094 (BRASIL, 2007b), de 24 de abril de 2007, dispõe sobre a implementação do Plano de Metas Compromisso Todos pela Educação pela União, em regime de colaboração com Municípios, Distrito Federal e Estados, e a participação das famílias e da comunidade, mediante programas e ações de assistência técnica e financeira, visando à mobilização social pela melhoria da qualidade da educação básica.

Para regulamentar o Art.66 da LDB (BRASIL, 1996), foi aprovada a Lei no 10.172 (BRASIL, 2001), que sancionou o Plano Nacional de Educação (PNE) para o período entre 2001 e 2010, e recentemente foi homologada a Lei no 13.005, de 25 de junho de 2014 (BRASIL, 2014), validando o Plano Nacional de Educação (PNE) para o período entre 2014 e 2024. 0 Plano Nacional tem características relevantes que repercutem na concepção e no desenho operacional dos planos estaduais e municipais. Assim definidos:

Trata-se de um plano nacional e não de um plano da União. ${ }^{3}$ Os objetivos e metas nele fixados são

3 Considerou-se aqui o conceito de União tal como figura no art. 18 da Constituição Federal: "Art. 18. A organização político-administrativa da República Federativa do Brasil compreende a União, os Estados, o Distrito Federal objetivos e metas da Nação brasileira. Cada Estado, o Distrito Federal e cada Município estão ali dentro como parte constitutiva. São as crianças, os jovens e os adultos de seus respectivos territórios os destinatários do esforço educacional proposto (BRASIL, 2001, p. 15).

Para Dourado (2011, p. 286), o PNE 20012010: “[...] sem especificação clara dos recursos financeiros para a implementação de suas metas, o transformou em uma simples carta de intenções". Sem estipular percentuais mínimos de investimentos para cada meta, essa efetivação financeira deu-se somente a partir de 2007, por meio do Plano de Desenvolvimento da Educação (PDE), implantado pelo presidente Luiz Inácio Lula, que gerou alguns programas implantados pelo Governo Federal, entre eles o REUNI (2007/2008). Segundo a Pesquisa "Avaliação do Plano Nacional de Educação: desafios e perspectivas", coordenada por Dourado (2011, p. 287), “[...] democratizar o acesso e garantir a permanência constitui enorme desafio, sobretudo ao se considerarem os indicadores educacionais e as condições objetivas da população, diante do cumprimento das metas do PNE".

Esses investimentos contribuíram bastante para a expansão da educação superior, principalmente no setor público. Lembrando que se trata de expansão das estruturas física e número de alunos. Referindo-se à expansão qualitativa que trata da gestão democrática mencionada na LDB (BRASIL, 1996) e à qualidade do processo de ensino-aprendizagem, principalmente no que diz respeito à formação do docente que atua na educação básica, ocorreram ações efetivas do MEC, a saber: a definição da formação em nível de graduação para a atuação na educação básica; a rede nacional de formação continuada; Pró-Letramento; Pró-Infantil; Pró-Licenciatura; projeto Educação em Direitos Humanos, entre outras. Para Aguiar (2011, p. 266),

e os Municípios, todos autônomos, nos termos desta constituição" (BRASIL, 1988). 
observa-se o desenvolvimento de políticas que contemplam a melhoria das condições de trabalho - salário, plano de carreira, capacitação e avaliação - impulsionadas, sobretudo, pelas demandas e pressões políticas de várias entidades, como a Confederação dos Trabalhadores da Educação (CNTE).

0 que se mostra inalterado nesses períodos analisados é a precariedade das políticas formativas. As alterações não conseguiram estabelecer uma proposta consistente para a formação do professor que atuará na educação básica, a fim de assegurar uma qualidade formativa que possibilitasse que a formação inicial preparasse um profissional apto a atuar nas escolas brasileiras. Tais políticas por meio de regulamentações, legislação, regras, procedimentos, normas, entre outros fatores, direcionaram as ações institucionais quase que exclusivamente para o atendimento dessas normas em detrimento do fazer pedagógico.

Para além dos dados quantitativos, há que se concretizar maior articulação entre órgãos e secretarias do MEC e destes com os sistemas de ensino, por meio de ações sistemáticas e de planejamento no intuito de oferecer, além de acesso, a possibilidade de permanência e agregar valor qualitativo que eleve o percentual de concluintes de fato preparados. Em meio aos grandes desafios que o Brasil tem que enfrentar, a melhora das condições educacionais é, certamente, uma prioridade.

Melhorar as condições educacionais implica aumentar a escolaridade; elevar os níveis de aprendizagem; ampliar e adequar a formação profissional - considerando as exigências do mundo do trabalho; tornar o sistema educacional mais eficaz na capacidade de produzir concluintes em cada etapa da escolarização na idade própria; ampliar a oferta, sobretudo na educação infantil, no ensino médio, na educação pós-médio (profissional) e na educação superior. (SAMPAIO, 2011, p. 61).

A ação do Estado necessita priorizar a educação pública para todos, assim como para cada um, gratuita para quem se beneficia, mas paga pelo contribuinte. Isso não se revela uma em- preitada fácil. Dourado (2011, p. 286) afirma que se faz necessário

Uma educação com qualidade social, em que a gestão seja democrática, como previsto na Constituição Federal de 1988, precisa ser priorizada no contexto do PNE 2014-20204 o que pressupõe garantir o direito à educação para todos, por meio de políticas públicas, materializadas em programas de ações articuladas, com acompanhamento e avaliação da sociedade, tendo em vista a melhoria dos processos de organização e gestão dos sistemas e das instituições educativas.

As políticas e ações do MEC podem contribuir para superar, na formação inicial e continuada, a dicotomia entre a teoria e a prática, e entre a formação pedagógica stricto sensu e a formação no campo de conhecimentos específicos.

Após análises dos PNE das duas últimas décadas, percebe-se que no texto de 2001/2010 os objetivos educacionais mostravam-se amplos, trazendo um grande desafio para superar a sua generalidade. Algumas metas indicadas eram na verdade diretrizes, gerando uma grande dificuldade de se criar critérios para avaliação da sua realização, visto que faltavam mecanismos para essa análise, bem como recursos financeiros. Houve avanços tímidos em termos de formação inicial e continuada no tocante às questões pedagógicas e de gestão democrática. Os avanços mais significativos se deram da metade para o final do plano, em investimentos financeiros para estruturação física das IES públicas e financiamentos para as instituições privadas, o que melhorou o acesso, mas não aumentou significativamente o número de concluintes.

O PNE 2014/2024 (BRASIL, 2014) está melhor distribuído entre metas e estratégias. A avaliação ainda é desafio, baseado no ranking comparativo, permeado por exames nacionais, provas e índices que não consideram a complexidade do processo educacional. Considera-se que propostas nacionais como o PNE necessitam um acompanhamento sistemático pelos órgãos oficiais envolvidos, assim como 
as comunidades e profissionais vinculados à área da educação, com o intuito de discutir, trabalhar e acompanhar o desenvolvimento e a efetivação das propostas contidas no documento, transformando ações previstas em práticas concretas de gestão da educação.

O cenário até aqui apresentado possibilita a compreensão de que a instituição da Política Nacional de Formação de Profissionais do Magistério da Educação Básica, que tem por base o Decreto no 6.755 (BRASIL, 2009), de 2009, partiu, entre outros, da constatação da existência de um grande número de professores sem a formação adequada para a etapa de ensino em que atuam, da apreensão de indicadores estatísticos que evidenciam a insuficiência de professores licenciados em algumas áreas, bem como da compreensão da importância da formação docente para o necessário avanço da qualidade do ensino no país.

Implementando a Política Nacional de Educação (BRASIL, 2007c), criaram-se vários programas de formação para os Profissionais do Magistério da Educação Básica, entre eles o Plano Emergencial Nacional de Formação de Professores da Educação Básica (PARFOR) (BRASIL, 2009). Entre os objetivos a serem alcançados por esta Política, destacam-se: identificar e suprir a necessidade das redes e sistemas públicos de ensino por formação inicial e continuada de profissionais do magistério; promover a integração da educação básica com a formação inicial docente, assim como reforçar a formação continuada como prática escolar regular que responda às características culturais e sociais regionais. Este artigo objetiva analisar os impactos desse programa de formação para os professores em exercício.

Nos relatórios institucionais foi possível analisar a proposição do Plano Nacional de Formação de Professores da Educação Básica (PARFOR), que foi ofertado pela universidade. Ele foi idealizado para atender a Política $\mathrm{Na-}$ cional de Formação de Profissionais do Magistério da Educação Básica (BRASIL, 2009), que instituiu a formação inicial e continuada dos docentes em exercício, sendo conduzido pela Coordenação de Aperfeiçoamento de Pessoal de Nível Superior (Capes). Como um Programa emergencial, tinha a incumbência de contribuir para que os professores em exercício da rede pública de educação básica tivessem acesso à formação superior em Licenciatura exigida pela Lei de Diretrizes e Bases da Educação Nacional (LDB) (BRASIL, 1996).

Entendeu-se que tal formação contribuiu de maneira direta para a qualificação profissional dos professores em exercício a partir de um curso de formação constituído por módulos integrados que visavam proporcionar a reflexão teórico-prático do saber docente e, indiretamente, para a melhoria da educação brasileira. O PARFOR na IES foi ofertado entre 2012 e 2017.

O Programa Institucional de Bolsa de Iniciação à Docência (PIBID) (BRASIL, 2010b) tinha como premissa essencial o aprimoramento e a valorização da formação docente destinados à atuação na Educação Básica. Como proposta, foram criadas bolsas para os estudantes vinculados a instituições de educação superior e que estavam matriculados nos cursos de licenciatura para apoiar o seu desenvolvimento e qualificação. A participação em projetos que permitiriam a iniciação à docência desenvolvidos em parceria de IES e escolas da rede pública de ensino asseguraria um apoio formativo, além de auxiliar na inserção à docência. No conjunto de ações de articulação da Universidade Tecnológica Federal do Paraná (UTFPR) com a formação inicial e continuada de professores para a educação básica, destacase a aprovação dos projetos institucionais de Programa Institucional de Bolsas de Iniciação à Docência (PIBID) e Residência Pedagógica (RP) (COORDENAÇÃO DE APERFEIÇOAMENTO DE PESSOAL DE NÍVEL SUPERIOR, 2018a), vinculados aos Editais Capes $n^{\circ} 6$ e 7/2018 (COORDENAÇÃO DE APERFEIÇOAMENTO DE PESSOAL DE NÍVEL SUPERIOR, 2018b), por meio dos quais foram liberadas mensalmente 387 bolsas de PIBID e 288 bolsas de RP, com 
início em agosto de 2018 e duração de 18 meses. Além das possibilidades formativas junto aos estudantes de licenciaturas envolvidos nos projetos em 12 campus da IES, as inciativas têm possibilitado o engajamento de professores da educação básica em outras ações e programas da Universidade, que envolvem atividades de extensão e pesquisa.

O Programa de Licenciaturas Internacionais foi uma iniciativa da Capes - que teve a sua primeira versão no ano de 2010. 0 apoio do Grupo de Coimbra de Universidades Brasileiras (GCUB) foi determinante para a criação desse programa, e os principais objetivos priorizaram a melhoria do ensino nos cursos de licenciatura e a formação de professores, bem como:

Ampliar a formação de docentes para o ensino básico no contexto nacional; ampliar e dinamizar as ações voltadas à formação de professores, priorizando a formação inicial desenvolvida nos cursos de licenciatura; apoiar a formulação e implementação de novas diretrizes curriculares para a formação de professores, com ênfase no Ensino Fundamental e no Ensino Médio. (COORDENAÇÃO DE APERFEIÇOAMENTO DE PESSOAL DE NÍVEL SUPERIOR, 2018).

A participação no Programa ocorria por meio de uma seleção de projetos elaborados por professores vinculados aos cursos de licenciatura no país e que tinham convênio de cooperação com uma universidade portuguesa. A seleção dos estudantes que participariam do programa era de responsabilidade da instituição proponente do projeto e todos os bolsistas que participassem do Programa de Licenciaturas Internacionais (PLI) obteriam o duplo diploma (graduação sanduíche), reconhecido pelas legislações educacionais brasileira e portuguesa. Para tal, eles deveriam cursar quatro semestres letivos em uma universidade portuguesa previamente definida e um período similar em sua instituição de origem, bem como obter um número mínimo de créditos acadêmicos nas universidades estrangeiras $\left(120 \mathrm{ETCS}^{4}\right)$,

4 European Train Control System. É um sistema europeu para reconhecimento dos créditos acadêmicos cursados permitindo uma dupla formação a partir da convalidação dessas disciplinas.

Os editais eram bastante exigentes em relação à arquitetura curricular dos bolsistas e estabeleciam que ambas as instituições assumissem compromissos com a formação acadêmica, e solicitassem que o colegiado do curso de origem analisasse as duas grades curriculares (universidade brasileira e universidade portuguesa), propondo um plano de estudos para cada bolsista e o aprove.

Além do colegiado, a Pró-Reitoria de Graduação ou órgão similar, bem como o Reitor ou Dirigente da IES, também assumiriam compromisso formal com as convalidações no momento em que assinassem os Termos de Cooperação Internacional e os Termos Aditivos específicos ao PLI. Todos esses cuidados visavam preservar a boa formação dos bolsistas, bem como evitar que eles viessem a ter dificuldades, no retorno ao Brasil, para a convalidação das disciplinas cursadas no exterior.

O PLI tinha um cunho social e solicitava, por meio de edital, que a participação no programa ocorresse somente para alunos advindos de escolas públicas de educação básica brasileira. Para isso, todo candidato à bolsa deveria comprovar que cursou a totalidade do ensino médio e pelo menos dois anos do ensino fundamental em instituições públicas. As exceções se voltavam para os alunos que foram bolsistas integrais em instituições privadas e comprovassem baixa renda familiar.

A oportunidade de intercâmbio para os alunos das licenciaturas brasileiras permitiu que os bolsistas e os professores responsáveis pelos projetos tivessem uma visão mais ampla e uma aquisição de experiências do processo formativo português, possibilitando utilizá-las na análise e avalição das suas próprias propostas de formação de professores em nível de licenciatura.

O Departamento de Educação de um dos campi da IES em questão propôs um projeto

pelos estudantes em diferentes instituições de educação superior. 
de formação de professores em conjunto com o Departamento de Física e o Departamento de Matemática, e dois projetos foram aprovados pela Capes nos anos de 2012-2014 e 20132015. Participaram na primeira versão sete alunos, sendo quatro do curso de Licenciatura em Matemática e três de Licenciatura em Física (2012-2014). Destes, os quatro de Licenciatura em Matemática permaneceram durante o período de dois anos. Para o segundo projeto aprovado, seis alunos foram contemplados, sendo quatro de Licenciatura em Física e dois de Licenciatura em Matemática. Todos permaneceram durante os dois anos previstos no Programa.

O acompanhamento dos bolsistas em Portugal ocorreu por meio de um programa criado para esse fim e batizado de Grupo de Orientação ao Licenciando (GOL), que visou ao acompanhamento e assessoramento ao bolsista no ensino universitário (processo de formação inicial aos conteúdos específicos para atuação na docência) e assistência à inserção profissional docente, no que se refere a como se aprende a ensinar. Esse Grupo constitui uma unidade de trabalho colaborativo que buscou analisar o processo de formação, bem como a tomada de decisões que auxiliaram ou solucionaram possíveis problemas (UNIVERSIDADE TECNOLÓGICA FEDERAL DO PARANÁ, 2012). Com apoio de uma equipe de professores da área de educação e das áreas específicas de física e matemática denominados "professores tutores", a equipe assumiu a incumbência de organizar, colaborativamente, a proposta de integração curricular do conjunto de disciplinas do curso para cada um dos estudantes em consonância com os dispositivos estabelecidos para a atribuição da dupla diplomação e acompanhar o desempenho de cada um deles. As estratégias de acompanhamento ocorreram por meio de ambientes virtuais, redes sociais, autoavaliação a partir de instrumentos investigativos e avaliação do professor tutor. Além dessas, as missões de trabalho previstas em Portugal pelo Programa, realizadas no início de cada semestre, permitiram uma aproximação física com os bolsistas para o acompanhamento do projeto.

No ano de 2014 não foi aberto edital e em 2015 o Departamento de Educação submeteu novamente uma proposta, desta vez em conjunto com os Departamentos de Física, Matemática e Química. A situação econômica e social do país interferiu na permanência deste programa e dos 40 projetos que estavam previstos, em edital, serem aprovados para o PLI, somente 18 foram contemplados. A IES não participou dessa nova edição.

Outros cursos também foram contemplados com a oportunidade do duplo diploma: o Curso de Licenciatura em Matemática do Campus Toledo, que participou do PLI ao encaminhar cinco alunos do curso para o intercâmbio de dois anos na Universidade do Minho, em Portugal; o curso de Letras do Campus Pato Branco; e o curso de Química do Campus Campo Mourão.

Outro programa nacional que apoiou os cursos de licenciatura também foi desenvolvido na instituição. 0 Programa de Apoio a Laboratórios Interdisciplinares de Formação de Educadores (LIFE) tem o propósito de estimular a criação de laboratórios com cunho interdisciplinar para a formação dos futuros professores da educação básica. A IES foi contemplada com o LIFE e teve a oportunidade de consolidar um laboratório que buscou atender ao indicado no Edital nº 067/2013 (COORDENAÇÃO DE APERFEIÇOAMENTO DE PESSOAL DE NÍVEL SUPERIOR, 2013), por meio da criação de um espaço que foi socializado entre os professores em formação das diferentes licenciaturas da instituição.

\section{Algumas considerações finais}

Este estudo faz parte de uma longa trajetória de investigações que têm analisado como a formação inicial e continuada de professores tem ocorrido em uma IES pública federal. Etapas como análise do perfil do egresso, compreensão das propostas curriculares e entendimento 
sobre o propósito formativo já foram abordadas pelo grupo de pesquisa.

A formação de professores que se insere no contexto da universidade estudada é bastante abrangente, significativa e apresenta caraterísticas e especificidades por estar vinculada a uma universidade tecnológica. Neste espaço entende-se que é inerente e necessário integrar nos cursos de formação de professores conhecimentos da dimensão pedagógica e tecnológica.

Nesse sentido, a formação de professores na IES iniciou com a necessidade de formação dos professores do ensino técnico, com a formação do Esquema I e II, cursos especiais de formação de professores, além da oferta de cursos de licenciatura desde de 2011 e a inserção em programas e políticas nacionais que visam contribuir para a formação de professores da educação básica.

Ressalta-se que a formação docente se faz pelo conjunto de ações individuais, coletivas e institucionais que buscam o aprimoramento do processo formativo como um todo. A história institucional revela que o percurso começou há muito tempo, mas ainda está longe de chegar ao seu destino, isto é, uma formação de professores para atuar na educação básica sustentada pela qualidade e excelência do processo.

Todas as iniciativas vinculadas às propostas institucionais de formação de professores sempre estiveram associadas a políticas nacionais, sem exceção. Isso significa afirmar que as políticas públicas são determinantes para que os processos se iniciem, para que as pessoas envolvidas com a formação comecem a criar, refletir, analisar, propor alternativas consistentes para a profissionalização docente. Pensar e transformar a educação em um país depende de atitudes concretas para modificá-la, por meio da proposição de programas, apoios, estímulos, parcerias e alternativas que visem essa alteração.

A exemplo, daria para destacar que quando o Plano Nacional de Educação solicitou em seus meandros que a formação docente deveria ter destaque nas políticas educacionais, existiu uma mobilização para que ela, de fato, se consolidasse. Instituições de educação superior, secretarias de educação em nível estadual e municipal, órgãos apoiadores das políticas educacionais, entre outros setores, iniciaram a viabilidade do atendimento desse propósito. Isso não significa afirmar que basta escrever uma meta para que ela aconteça na prática, no entanto, ao emergir tal necessidade, iniciam-se as reflexões em busca da consolidação dessa mesma meta.

Programas como o Esquema I e II, PLI, PARFOR, LIFE, PIBID alavancaram as ações institucionais voltadas para a formação de professores. É possível que, sem tais incentivos, uma universidade tecnológica permanecesse responsável somente pela formação na área das engenharias e tecnologias, sem abrir a alternativa para a formação de professores. As políticas vieram, ecoaram nos bastidores institucionais e se transformaram em ações concretas e, no momento, pela existência dos cursos de formação de professores, pesquisadores se debruçam sobre esses processos formativos, contribuindo, mesmo que modestamente, para a melhoria e aprimoramento dos cursos de licenciatura da IES.

Nos bastidores institucionais encontramse estudantes estimulados com a aprendizagem profissional para a docência, envolvidos com os programas existentes, contando que tiveram a oportunidade de participar de atividades pouco imaginadas antes do ingresso na licenciatura. Eles acreditam na educação e já emitem análises sobre possibilidades de atuação e aprimoramento profissional, e têm a liberdade de indicar melhorias para a mudança dos seus próprios cursos de formação como representantes dos órgãos como colegiados, como organizadores de semanas acadêmicas e participantes de eventos na área de educação na condição de apresentadores de trabalhos científicos.

A interrupção do PARFOR significou que os bacharéis deixaram de ter apoio formativo 
para a docência; eles permanecem ministrando aulas a partir da sua experiência enquanto observador de aulas, condição existente desde o seu ingresso na escola fundamental. Na medida em que atuam sem serem profissionais qualificados para o magistério, tendem a comprometer o processo como um todo e, talvez, inibir o avanço das conquistas feitas até o momento.

Todavia, percebe-se que uma IES pode permanecer apoiando a formação de professores, pois na medida em que os cursos de licenciaturas têm espaços consolidados para análise e reflexão das suas próprias propostas, o aprimoramento permanecerá existindo.

Assim, considera-se que a formação de professores implica em uma permanente análise e reflexão, pois à medida que se avança, novos desafios se apresentam, desencadeando novas necessidades e novas análises e reflexões; é o movimento dialético impulsionando os formadores de professores.

\section{REFERÊNCIAS}

AGUIAR, Marcia Angela da S. A formação dos profissionais da educação no contexto atual e o PNE 2011-2020: avaliação e perspectivas. In: DOURADO, Luiz Fernandes (org.). Plano Nacional de Educação (2011 - 2012): avaliação e perspectivas. Belo Horizonte: Autêntica, 2011.

BARDIN, L. Análise de conteúdo. Lisboa: Edições 70, 2009.

BRASIL. Lei no 5.540, de 28 de novembro de 1968. Fixa normas de organização e funcionamento do ensino superior e sua articulação com a escola média, e dá outras providências. Brasília, DF, 1968. Disponível em: https://www2.camara.leg.br/ legin/fed/lei/1960-1969/lei-5540-28-novembro1968-359201-publicacaooriginal-1-pl.html. Acesso em: 30 abr. 2018.

BRASIL. Decreto Lei no 464, de 11 de fevereiro de 1969. Estabelece normas complementares a Lei 5.540 e dá outras providências. Brasília, DF, 1969. Disponível em: https://legis.senado.leg.br/ norma/523565. Acesso em: 30 abr. 2018.

BRASIL. Portaria n.o 432, de 19 de julho de 1971. Estabelece as normas relativas aos cursos superiores de formação de professores de disciplinas especializadas para habilitação do ensino médio, relativas às atividades econômicas primárias, secundárias e terciárias. Brasília, DF, 1971a. Disponível em: http://siau.edunet.sp.gov. br/ItemLise/arquivos/notas/port432_71.htm. Acesso em: 30 abr. 2018.

BRASIL. Lei no 5.692, de 11 de agosto de 1971. Fixa Diretrizes e Bases para o ensino de $1^{\circ}$ e $2^{\circ}$ graus, e dá outras providências. Brasília, DF, 1971b. Disponível em: https://presrepublica.jusbrasil. com.br/legislacao/128525/lei-de-diretrizes-ebase-de-1971-lei-5692-71. Acesso em: 30 abr. 2018.

BRASIL. Parecer CNE no 335, de 04 de junho de 1982. Analisa a proposta do programa Esquema I e Esquema II destinados à formação pedagógica dos professores. Brasília, DF, 1982a. Disponível em: http://www.dominiopublico.gov.br/download/ texto/cd010904.pdf. Acesso em: 04 mar. 2020.

BRASIL. Lei no 7.044, de 18 de outubro de 1982. Altera dispositivos da Lei $n=5.692$, de 11 de agosto de 1971, referentes a profissionalização do ensino de $2^{\circ}$ grau. Brasília, DF, 1982b. Disponível em: https://www2.camara.leg.br/legin/fed/ lei/1980-1987/lei-7044-18-outubro-1982357120-publicacaooriginal-1-pl.html. Acesso em: 30 abr. 2018.

BRASIL. Constituição da República Federativa do Brasil. Brasília, DF, 1988. Disponível em: http:// www.planalto.gov.br/ccivil_03/constituicao/ constituicao.htm. Acesso em: 04 mar. 2020.

BRASIL. Lei no 9.394, de 20 de dezembro de 1996. Estabelece as diretrizes e bases da educação nacional. Brasília, DF, 1996.

BRASIL. Resolução CNE no 2, de 26 de junho de 1997. Dispõe sobre os programas especiais de formação pedagógica de docentes para as disciplinas do currículo do ensino fundamental, do ensino médio e da educação profissional em nível médio. Brasília, DF, 1997. Disponível em: http:// portal.mec.gov.br/setec/arquivos/pdf/Res02.pdf. Acesso em: 30 abr. 2018.

BRASIL. Ministério da Educação. Proposta de diretrizes para a formação inicial de professores da Educação Básica, em cursos de nível superior. Brasília, DF, 2000a. Disponível em: http://portal. mec.gov.br/cne/arquivos/pdf/basica.pdf. Acesso em: 30 abr. 2018.

BRASIL. Câmara dos Deputados. Decreto no 3.462, 
de 17 de maio de 2000. Dá nova redação ao art. 8o do Decreto no 2.406 , de 27 de novembro de 1997, que regulamenta a Lei no 8.948 , de 8 de dezembro de 1994. Brasília, DF, 2000b. Disponível em: https://www2.camara.leg.br/legin/fed/ decret/2000/decreto-3462-17-maio-2000377149-publicacaooriginal-1-pe.html. Acesso em: 08 mar. 2020.

BRASIL. Lei no 10.172, de 9 de janeiro de 2001. Aprova o Plano Nacional de Educação e dá outras providências. Disponível em: http://portal.mec. gov.br/arquivos/pdf/L10172.pdf. Acesso em: 04 ago. 2018.

BRASIL. Decreto no 6.096, de 24 de abril de 2007. Institui o Programa de Apoio a Planos de Reestruturação e Expansão das Universidades Federais - REUNI. Brasília, DF, 2007a. Disponível em: http://www2.camara.leg.br/legin/fed/ decret/2007/decreto-6096-24-abril-2007553447-norma-pe.html. Acesso em: 30 abr. 2018.

BRASIL. Decreto no 6.094, de 24 de abril de 2007. Dispõe sobre a implementação do Plano de Metas Compromisso Todos pela Educação, pela União Federal, em regime de colaboração com Municípios, Distrito Federal e Estados, e a participação das famílias e da comunidade, mediante programas e ações de assistência técnica e financeira, visando a mobilização social pela melhoria da qualidade da educação básica. Brasília, DF, 2007b. Disponível em: http://www.planalto.gov.br/ccivil_03/_ato20072010/2007/decreto/d6094.htm. Acesso em: 04 ago. 2018.

BRASIL. Ministério da Educação. 0 Plano de Desenvolvimento da Educação: razões, princípios e programas. Brasília, DF, 2007c. Disponível em: http://portal.mec.gov.br/arquivos/livro/livro.pdf. Acesso em: 04 ago. 2018.

BRASIL. Decreto n.o 6.755 , de 29 de janeiro de 2009. Institui a Política Nacional de Formação de Profissionais do Magistério da Educação Básica, disciplina a atuação da Coordenação de Aperfeiçoamento de Pessoal de Nível Superior CAPES no fomento a programas de formação inicial e continuada, e dá outras providências. Brasília, DF, 2009. Disponível em: https://www2.camara. leg.br/legin/fed/decret/2009/decreto-6755-29janeiro-2009-585786-norma-pe.html. Acesso em: 04 ago. 2018.

BRASIL. Parecer Conaes no 4, de 17 de junho de 2010. Estabelece o Núcleo Docente Estruturante. Brasília, DF, 2010a. Disponível em: http://portal.mec.gov.br/index.php?option=com docman\&view=download\&alias=6884-parecerconae-nde4-2010\&category_slug=outubro-2010pdf\&Itemid=30192. Acesso em: 03 jul. 2018.

BRASIL. Decreto no 7.219, de 24 de junho de 2010. Dispõe sobre o Programa Institucional de Bolsa de Iniciação à Docência - PIBID e dá outras providências. Brasília, DF, 2010b. Disponível em: http://www.planalto.gov.br/ccivil_03/_Ato20072010/2010/Decreto/D7219.htm. Acesso em: 04 ago. 2018.

BRASIL. Ministério da Educação. Lei no 13.005, de 25 de junho de 2014. Aprova o Plano Nacional de Educação (PNE) e dá outras providências. Brasília, DF, 2014. Disponível em: http://www.proec. ufpr.br/download/extensao/2016/creditacao/ PNE\%202014-2024.pdf. Acesso em: 08 mar. 2020.

BRASIL. Resolução CNE/CP no 2, de 10 de julho de 2015. Define as Diretrizes Curriculares Nacionais para a formação inicial em nível superior (cursos de licenciatura, cursos de formação pedagógica para graduados e cursos de segunda licenciatura) e para a formação continuada. Brasília, DF, 2015. Disponível em: http://portal.mec.gov.br/ docman/agosto-2017-pdf/70431-res-cne-cp-00203072015-pdf/file. Acesso em: 04 ago. 2018.

COORDENAÇÃO DE APERFEIÇOAMENTO DE PESSOAL DE NÍVEL SUPERIOR (CAPES). Programa de Licenciaturas Internacionais - Portugal. Editais 2010, 2011, 2012 e 2013. Disponível em: https://www.capes.gov.br/bolsas-e-auxiliosinternacionais/pais/218-multinacional/9637licenciaturas-internacionais-portugal. Acesso em: 04 ago. 2018.

COORDENAÇÃO DE APERFEIÇOAMENTO DE PESSOAL DE NÍVEL SUPERIOR (CAPES). Programa de Apoio a Laboratórios Interdisciplinares de Formação de Educadores - LIFE. Edital no 067/2013. Disponível em: https://www.capes. gov.br/images/stories/download/editais/ Edital_067_2013_SICAPES-LIFE.pdf. Acesso em: 30 abr. 2018.

COORDENAÇÃO DE APERFEIÇOAMENTO DE PESSOAL DE NÍVEL SUPERIOR (CAPES). Portaria no 46, de 11 de abril de 2016. Aprova o Regulamento do Programa Institucional de Bolsa de Iniciação à Docência - PIBID. Disponível em: https://www.capes.gov.br/images/stories/ download/legislacao/15042016-Portaria-46Regulamento-PIBID-completa.pdf. Acesso em: 04 ago. 2018. 
COORDENAÇÃO DE APERFEIÇOAMENTO DE PESSOAL DE NÍVEL SUPERIOR (CAPES). Portaria no 38, de 28 de fevereiro de 2018. Institui o Programa de Residência Pedagógica. Brasília, DF, 2018a. Disponível em: https://www.capes.gov.br/ images/stories/download/legislacao/28022018Portaria_n_38-Institui_RP.pdf. Acesso em: 04 mar. 2020.

COORDENAÇÃO DE APERFEIÇOAMENTO DE PESSOAL DE NÍVEL SUPERIOR (CAPES). Programa Institucional de Bolsa de Iniciação à Docência (PIBID). Chamada pública para apresentação de propostas. Editais no $\mathbf{6 / 2 0 1 8 ~ e ~ 7 / 2 0 1 8 . ~ B r a s i ́ l i a , ~}$ DF, 2018b. Disponível em: https://www.capes.gov. br/images/stories/download/editais/01032018Edital-7-2018-PIBID.pdf. Acesso em: 04 ago. 2018.

DOURADO, Luiz Fernandes. Plano Nacional de Educação como política de Estado: antecedentes históricos, avaliação e perspectivas. In: DOURADO, Luiz Fernandes (org.). Plano Nacional de Educação (2011 - 2012): avaliação e perspectivas. Belo Horizonte: Autêntica, 2011.

INSTITUTO NACIONAL DE ESTUDOS E PESQUISAS EDUCACIONAIS ANÍSIO TEIXEIRA (INEP). Sinopse Estatística da Educação Superior 2010. Brasília, DF, 2010. Disponível em: http://portal.inep.gov.br/ basica-censo-escolar-sinopse-sinopse. Acesso em: 08 mar. 2020.

INSTITUTO NACIONAL DE ESTUDOS E PESQUISAS EDUCACIONAIS ANÍSIO TEIXEIRA (INEP). Sinopse Estatística da Educação Superior 2017. Brasília, DF, 2018. Disponível em: http://portal.inep.gov.br/ basica-censo-escolar-sinopse-sinopse. Acesso em: 03 jul. 2018.

INSTITUTO NACIONAL DE ESTUDOS E PESQUISAS EDUCACIONAIS ANÍSIO TEIXEIRA (INEP). Sinopse Estatística da Educação Superior 2018. Brasília: Inep, 2019. Disponível em: <http://portal.inep.gov. $\mathrm{br} /$ basica-censo-escolar-sinopse-sinopse $>$. Acesso em: 08 mar. 2020.

MAZZOTA, Marcos José da Silveira. Formação de professores para as disciplinas específicas de segundo grau no Brasil. São Paulo: CENAFOR/ COMTEC/SIEFOR, 1985.

SÁ-SILVA, J. R.; ALMEIDA, C. D.; GUINDANI, J. F. Pesquisa documental: pistas teóricas e metodológicas. Revista Brasileira de História \& Ciências Sociais, ano 1, n. 1, jul. 2009.

SAMPAIO, Carlos Eduardo Moreno. Monitoramento e avaliação do Plano Nacional de Educação. In: DOURADO, Luiz Fernandes (org.). Plano Nacional de Educação (2011 - 2012): avaliação e perspectivas. Belo Horizonte: Autêntica, 2011.

UNIVERSIDADE TECNOLÓGICA FEDERAL DO PARANÁ (UTFPR). Departamento de Educação (DEPED). Da formação inicial à inserção profissional docente: um programa de acompanhamento, orientação e desenvolvimento do processo formativo nas áreas de física e matemática. Programa de Licenciaturas Internacionais (PLI) CAPES - Edital 008/2012. Curitiba, 2012.

UNIVERSIDADE TECNOLÓGICA FEDERAL DO PARANÁ (UTFPR). Relatório de Gestão do exercício de 2018. Curitiba: EDUTFPR, 2019. 